\title{
Inbreeding depression and partial selfing: evolutionary implications of mixed-mating in a coastal endemic, Silene douglasii var. oraria (Caryophyllaceae)
}

\author{
SUSAN R. KEPHART*, ERICA BROWN \& JEREMY HALL \\ Department of Biology, Willamette University, Salem, Oregon 97301, U.S.A.
}

\begin{abstract}
Recent studies have found moderate to high levels of selfing in plants despite high inbreeding depression. Because both factors influence the evolution and persistence of rare plants, we conducted glasshouse and field studies of pollination and inbreeding in Silene douglasii var. oraria, a perennial tetraploid endemic to coastal prairies. We detected: (i) variation in reproduction or inbreeding depression among life stages, years and maternal families; (ii) partial selfing yet higher relative fitness in outcrossed than selfed progeny; (iii) differing values of selfing and inbreeding depression using population means vs. matched maternal families. Fruit and seed production varied significantly with pollination treatment and year in flowers manipulated in situ during three seasons of growth. Handpollinations providing pollen in excess of ovule production in 1996 yielded more seeds than marked, open-pollinated flowers, implying pollen limitation of seed production. However, among-year differences in reproductive success after open-pollination (i.e. values equivalent to autogamy, selfing or outcrossing) suggest that pollination levels also vary temporally. In pollinations matched by maternal family, selfing yielded significantly fewer seeds than outcrossing. Fitness differences between inbred and outbred progeny were significant $(P<0.05)$ for seed production, percentage germination, and biomass or fecundity, but not for survival. Maternal family data gave selfing rates intermediate between obligate outcrossers and predominant selfers $(S=0.34-0.51)$, but population-wide means gave unusually high values $(S=1.1-1.6)$. Cumulative inbreeding depression was $76 \%$ for maternal families, and $70-85 \%$ using population means; in all cases, inbreeding depression values were high in early and late life stages, and lowest for survival. Thus far, reproductive assurance offers the most cogent explanation for the coexistence of moderate selfing and high inbreeding depression in this strongly protandrous Silene once thought to be highly outcrossing. This possibility merits further study in other rare plants with mixed-mating systems, where inbreeding depression and pollinator scarcity may both compromise population persistence and raise the threshold below which selfing is favoured by evolution.
\end{abstract}

Keywords: breeding systems, Caryophyllaceae, inbreeding depression, outcrossing, selfing, Silene.

\section{Introduction}

Inbreeding depression is a dynamic feature of populations, one that purportedly evolves in tandem with mating systems, and is a potentially powerful selective force for maintaining outcrossing in natural populations (Holsinger, 1988; Jarne \& Charlesworth, 1993). It counteracts the automatic transmission advantage of self-pollination, hence classical theoretical models of inbreeding depression $(\delta)$ once predicted that evolution-

*Correspondence. E-mail: skephart@willamette.edu

(C) 1999 The Genetical Society of Great Britain. arily stable populations would be either mostly selfing with low $\delta$ or largely outcrossing with high $\delta$ (e.g. Lande $\&$ Schemske, 1985). Yet despite an overall decline in $\delta$ with selfing in angiosperms, high inbreeding depression can occur in populations with moderate to high selfing, particularly if mildly deleterious alleles resist selective removal (Eckert \& Barrett, 1994; Latta \& Ritland, 1994; Johnston \& Schoen, 1996; Sakai et al., 1997).

Historical and ecological factors also influence the origin and evolutionary consequences of selfing and inbreeding depression. Thus, inbreeding is often less deleterious if a prior history of selfing has purged 
recessive lethals than if highly outcrossing populations undergo severe reductions in population size (Lande \& Schemske, 1985; Runyeon \& Prentice, 1996). If plant fitness is pollinator-limited, reproductive assurance may explain why partial selfing is favoured even at $\delta$-values greater than 0.5 (Piper et al., 1986; Lloyd, 1992). Reproductive assurance may be more important as a selective factor than is widely recognized: in nearly 100 studies, $42 \%$ of plants exhibited higher, short-term, female reproductive success after pollen addition (Young \& Young, 1992; but see Eckert \& Schaeffer, 1998).

Rare or endemic taxa may be especially susceptible to pollen limitation and pollinator scarcity, but few empirical studies (e.g. Norman et al., 1995, 1997) have examined both pollination and inbreeding in these groups. The fitness reductions associated with selfing at different life stages and ploidies are incompletely known even for common plants (Husband \& Schemske, 1996; Johnston \& Schoen, 1996), much less in relation to population structure (Waller, 1993) or levels of pollination (e.g. Ramsey \& Vaughton, 1996). Low mutational load is predicted in polyploids, but whether it lowers extinction rates in selfing populations is still uncertain (Lande \& Schemske, 1985; Schoen et al., 1997). Overall, inbreeding depression is likely to be a crucial predictor of persistence, especially in small or rare populations with little access to gene flow (e.g. Lesica, 1993; Newman \& Pilson, 1997).

Insect-pollinated plants with mixed-mating systems offer excellent opportunities for understanding the role of genecological factors on the evolution and maintenance of partial selfing. The mostly northern hemispheric genus Silene (Caryophyllaceae) and its close relatives include both rare and common perennials, are frequently outcrossed via diurnal or nocturnal pollinators, and possess diverse sexual systems including obligate dioecy, gynodioecy and dichogamy (Jennersten, 1988; Pettersson, 1991; Shykoff, 1992).

We used experimental crosses to evaluate inbreeding depression for different years and life stages in natural and glasshouse populations of $S$. douglasii var. oraria, a perennial tetraploid endemic to coastal Oregon. We asked several questions. (i) What forms of pollination and mating occur in this cosexual, protandrous Silene? (ii) If evident, does the level of inbreeding depression best fit predictions for predominantly selfing or outcrossing angiosperms? (iii) How might levels of natural pollination and inbreeding depression interact to influence the evolution of selfing? Variety oraria provides a good system for understanding why partial selfing might evolve in outcrossing perennials: the large flowers, dichogamy, and nectar and pollen rewards suggest a history of pollinator-mediated outcrossing, but self- compatibility and infrequent visitors imply a mixedmating system. Because monomorphism in the allozymes surveyed (Kephart, unpubl. data) led us to assess mating structure from crossing data, we also compared selfing and $\delta$-values based on population means with orthogonal measures from maternal families (see Latta \& Ritland, 1994).

\section{Materials and methods}

\section{Study organism and site history}

Variety oraria is the rarest of three distinct varieties of $S$. douglasii, and a state-threatened plant found in relatively undisturbed coastal prairie at three, disjunct sites from Neahkanie Mountain south to Cascade Head, near Lincoln City, OR. Our study is part of a long-term investigation of population variability at Cascade Head, a UNESCO site where over 1000 plants occur on grassy slopes and rocky bluffs dominated by Festuca idahoensis (Kephart \& Paladino, 1997). We gathered field data for three seasons, culminating in glasshouse studies during 1996-97.

Silene douglasii is a tap-rooted perennial found in compact clumps with one to 200 or more flowers (Kephart \& Paladino, 1997). Geitonogamy is possible, and each dichasium usually produces three to nine white flowers. Anthers dehisce in two sets prior to exsertion of three papillate stigmas. Hymenopterans and dipterans visit nectar- and pollen-laden flowers; the most common visitor, Lasioglossum sp., is a halictid bee that carries pollen of at least 11 species (Brown \& Kephart, unpubl. data).

\section{Breeding system and pollination experiments}

For three field seasons from 1982 to 1996, we gathered data on the efficacy of various exclusion and handpollination treatments for over 400 flowers on 75 randomly chosen plants. These comparisons (Table 1) allowed us to assess: (i) whether agamospermy occurs (fruit production without pollination or fertilization); (ii) whether spontaneous autogamy (i.e. autonomous selfing in the absence of pollen vectors) is possible despite protandry; and (iii) if capsule formation or seed production differ on open-pollinated, or hand-pollinated selfed and crossed flowers. We marked three to nine inflorescences/plant based on clump size. Flowers for pollination treatments were standardized for floral position to avoid differential resource allocations based on flowering time or the proximity of photosynthateproducing leaves. We tagged and emasculated flowers in late bud stage except for open-pollination and autogamy treatments (Table 1). Pollen from one to three dehiscing 
Table 1 Breeding system experiments in Silene douglasii var. oraria by year and treatment. $N$ is the remaining sample of flowers after losses caused by herbivory and mechanical damage. All hand-pollinated flowers were emasculated

\begin{tabular}{|c|c|c|}
\hline Treatment or comparison & $\operatorname{Year}(N)$ & Evaluation \\
\hline 1. B (with anther removal) & $1982(22), 1986(15), 1996(25)$ & $\begin{array}{l}\text { Test for nonpseduogamous agamospermy and } \\
\text { contamination during anther removal }\end{array}$ \\
\hline 2. B (anthers intact) & $1982(50), 1986(18), 1996(20)$ & Test for unassisted autogamous selfing \\
\hline $\begin{array}{l}\text { 3. B (hand-pollinated with } \\
\text { self- or cross-pollen) }\end{array}$ & $1986(36), 1996(51)$ & Test for inbreeding depression \\
\hline 4. O (anthers removed) & $1996(20)$ & $\begin{array}{l}\text { Test for fruit-set via pollen deposition by insects in } \\
\text { the absence of intraflower selfing }\end{array}$ \\
\hline 5. $\mathrm{O}$ (anthers intact) & 1982 (27), $1986(15), 1996(26)$ & $\begin{array}{l}\text { Natural pollination; fruit and seed production } \\
\text { resulting from insect-mediated transfer }+ \text { selfing }\end{array}$ \\
\hline $\begin{array}{l}\text { Related comparisons: } \\
\text { 6. Case } 2 \text { vs. } 5\end{array}$ & \multirow{2}{*}{\multicolumn{2}{|c|}{$\begin{array}{l}\text { (a) More fruits or seeds in } 5 \text { vs. } 2 \text { supports insect-mediated transfer by pollen or } \\
\text { nectar-feeders; } \\
\text { (b) no difference suggests fruits from open-pollinations are largely the result of autogamy } \\
\text { (a) Higher seed production in } 3 \text { vs. } 5 \text { (for both selfs and crosses) implies pollen limitation of } \\
\text { fruit-set in the field; } \\
\text { (b) lower fitness of self-pollinated progeny at various life stages (e.g. seed production) } \\
\text { supports inbreeding depression. }\end{array}$}} \\
\hline 7. Case 3 vs. 5 & & \\
\hline
\end{tabular}

B, bagged flowers; O, open-pollinated.

anthers was applied evenly across stigmas for selfs and outcrosses. We rebagged flowers after pollination, and collected mature capsules prior to dehiscence.

Sets of open-, cross- and self-pollinations occurred on the same plants to control for genetic and maternal effects (Lynch, 1988); we hand-pollinated plants in the field to ensure a selective regime comparable to that for naturally occurring open-pollinations (see review by Uyenoyama et al., 1993). We also collected openpollinated capsules from flowers tagged on nearby plants that were not manipulated for cross- or selfpollination to ensure that differences in fruit and seed production on experimental plants did not result from resource constraints related to supplemental pollination (Zimmerman \& Pyke, 1988). Extensive browsing of flowers by deer in 1982-84 reduced initial sample sizes by over $60 \%$, so in 1986 and 1996 two flowers were assigned to each open-pollination treatment to assure a sufficient sample after herbivory. Fine mesh covers on bagged flowers also limited browsing.

Comparative measures included fruit production (no. fruits/no. flowers marked or hand-pollinated), seed number per capsule (filled, presumably viable, seeds only), percentage of aborted ovules, and mean seed weight (weight of filled seeds in each capsule/no. filled seeds). (Abortive, unfilled seeds were small, flattened structures lacking developed embryos, whereas unfertilized ovules were minute.) We applied $t$-tests and ANOvAs (using Tukey's HSD for multiple pairwise comparisons), unless conditions for normality and homogeneity of variances were not met. If data could not be satisfactorily transformed, we used nonparametric tests (e.g. Mann-Whitney, Kruskall-Wallis). Deviations are standard errors (SE), unless otherwise noted.

\section{Measures of selfing rates}

The pollination treatments also provided populationlevel estimates of selfing rates. Because low variability and tetraploidy precluded using allozyme-based data, we estimated selfing rates $(S)$ from the relative performance (RP) of hand-outcrossed progeny (x) in relation to open-pollinated (o) and hand-selfed (s) progeny, where:

$S=\left(\begin{array}{lll}\mathrm{RP}_{\mathrm{x}} & \mathrm{RP}_{\mathrm{o}}\end{array}\right) /\left(\begin{array}{ll}\mathrm{RP}_{\mathrm{x}} & \mathrm{RP}_{\mathrm{s}}\end{array}\right)$

(Johnston \& Schoen, 1996). Although selfing rates based on fitness differences among progeny types can be problematic because of equivalence (e.g. hand-pollinations may provide supplemental pollen relative to openpollinated flowers), they are useful predictors of the mating system if derived from similarly treated flowers on the same maternal plants, and from traits measured early in the life cycle (Charlesworth, 1988; Lande et al., 1994). We used percentage viable seed (100 - percentage 
aborted seed) and percentage germination to compute primary selfing rates. This ensured equivalence in that viable or germinable progeny occur only in flowers with enough pollen to set fruit. Seeds of selfs might abort before germination (underestimating $S$ ), so we corrected germination values for such losses by computing $v$, the fitness ratio of selfed/crossed progeny (Mayer et al., 1996):

$S_{0}=S_{1} /\left[S_{1}(1 \quad v)+v\right]$,

where $S_{0}$ is the adjusted selfing rate and $S_{1}$ is the unadjusted germination selfing rate.

\section{Inbreeding depression}

We compared the fitnesses of selfed and outcrossed progeny for crosses paired by maternal family at four different stages: (i) fruit and seed production of maternal parents after in situ matings described above; (ii) progeny seed germination; (iii) survival of seedlings; and (iv) growth or fecundity of first-generation progeny. The last three stages were assessed for each maternal family in the glasshouse where environmental factors could be controlled; later progeny transplants into natural environments were precluded by possible habitat disruption. Thus our estimates of inbreeding depression are conservative if higher values occur under actual field conditions (e.g. Sabatia, Dudash, 1990; but see Willis, 1993; Norman et al., 1997). We determined levels of $\delta$ at each stage from the relative performance ratios of selfed $\left(w_{\mathrm{s}}\right)$ and outcrossed progeny $\left(w_{\mathrm{c}}\right)$ for each maternal parent, with $\delta=1-w_{\mathrm{s}} / w_{\mathrm{c}}$.

To compare how far estimates of inbreeding depression based on population averages deviated from those derived from paired maternal families, we established two sets of inbreeding depression trials measured for each life stage. For seed and fruit production, we first computed population-wide inbreeding depression based on means of open-, cross- and self-pollinations (trial 1). Secondly, we computed inbreeding depression levels for all of the matched pairs of selfed and outcrossed flowers for which both types set fruit on individual maternal plants in the field (11 of 25 maternal parents). Similarly, to evaluate differences in germination, survival, growth, and/or reproduction with pollination type, we compared two trials. In the first trial, open-, cross- and self-pollinated capsules were selected at random from those harvested in each category, whereas in the second trial, we ensured that capsules for cross- and selfpollinated progeny were both available in each maternal family. Seed coats were nicked prior to planting in a 1:1:2 mix of perlite, pumice and loam; we scored germination as cotyledon or radicle emergence at soil level, computing means at 15, 40 and 60 days. No deaths occurred before 15 days, and we tracked seedlings individually in trial 2 to ensure that any mortality after this time did not affect germination scores. In both trials, we rotated pots to avoid position effects, provided light for 10-14 h per day, and fertilized several times before transplanting.

To measure trial 1 survival and fecundity, we randomly selected progeny of open-, cross- and selfpollinations from cohorts of germinated seedlings and surviving plants. We scored survival at 4 months, as the earliest flowering plants formed buds and flowers. We postulated initially that fecundity would best predict lifetime survival and reproduction, and estimated cumulative inbreeding depression based on relative fitnesses at three life stages: seed production, 15-day germination, and a composite fecundity score (including three parameters: number of days to first flowering, and the height and flower number of the first inflorescence). We used the mean $\delta$ of this fecundity score to compute cumulative inbreeding depression. Plants with larger biomass flowered earlier, so we inverted the number of days between germination and flowering prior to computing relative fitness.

For trial 2 plants, we scored seedling survival at 60 and 180 days, biomass at 2 months, and reproduction at 170 days. Very few selfed progeny flowered, so we applied a flowering index, assigning a relative score of 1 to vegetative plants and scores of $2-5$, respectively, to plants with at least one bud (2), open flower (3), senescent flower (4) or capsule (5). To avoid destructive harvesting of rare plants, we used a biomass measure equal to the product of the number of leaf pairs and the leaf area $(1 \times w)$ for the largest leaf of each plant. (Each leaf pair on small axillary shoots was assigned a value of 0.10 relative to older leaf pairs of the primary shoot.) The resulting index showed a significant regression with above-ground dry weight $\left(r^{2}=0.90, P<0.001\right)$ for 15 plants measured, harvested, and dried at $22^{\circ} \mathrm{C}$ for 2.5 weeks and $38^{\circ} \mathrm{C}$ for $3 \mathrm{~h}$. We maintained plants from each maternal family for over 10 months, but the 2-month biomass data reflect important initial growth differences that are absent from later estimates of biomass or fecundity (i.e. some plants die before further measurement).

For trial 2 plants, we developed paired, maternally based estimates of cumulative fitness and inbreeding depression. We multiplied the relative fitness ratios for each maternal family for four different life stages (seed production - germination $\cdot$ survival growth) and subtracted this cumulative fitness from 1 . The grand mean of these values of $\delta$ across maternal parents is the overall estimate of cumulative inbreeding depression. We also calculated estimates using population-level fitness ratios (Johnston \& Schoen, 1994), and relative fitnesses for 
Table 2 Relative performance of selfed and outcrossed progeny in Silene douglasii var. oraria based on maternal families $(N M$, number of maternal parents) at different life cycle stages, trial 2

\begin{tabular}{|c|c|c|c|c|c|}
\hline Life cycle stages and traits & $N M$ & Self & Outcross & $\begin{array}{l}\text { Paired } \\
t \text {-value }\end{array}$ & $\delta$ \\
\hline \multicolumn{6}{|l|}{ I. Seed production } \\
\hline Seed number/capsule (with filled seeds only) & 11 & $25.8 \pm 6.4$ & $46.5 \pm 6.6$ & $2.5^{*}$ & 0.29 \\
\hline $\begin{array}{l}\text { Seed number/capsule (including zero values } \\
\text { for fruits with only aborted seeds) }\end{array}$ & 18 & $12.8 \pm 4.6$ & $31.4 \pm 6.7$ & $2.7 *$ & 0.59 \\
\hline $\begin{array}{l}\text { Percentage seed-set } \\
\text { (no. seeds/no. aborted ovules }+ \text { seeds) }\end{array}$ & 11 & $38.2 \pm 10.3$ & $68.7 \pm 9.3$ & $2.4^{*}$ & 0.30 \\
\hline Mean seed weight/capsule (mg) & 11 & $0.93 \pm 0.10$ & $0.93 \pm 0.08$ & $0.7 \mathrm{NS}$ & 0.01 \\
\hline $\begin{array}{l}\text { II. Germination } \\
\text { Percentage seed germination at } 60 \text { days (see also Fig. 4) }\end{array}$ & 11 & $38.4 \pm 9.5$ & $65.8 \pm 8.3$ & $4.4 * * *$ & 0.41 \\
\hline \multicolumn{6}{|l|}{ III. Survival } \\
\hline $\begin{array}{r}\text { Seedling survival (\%) to: } 0-60 \text { days } \\
60-180 \text { days }\end{array}$ & $\begin{array}{l}9 \\
8\end{array}$ & $\begin{array}{l}96.2 \pm 0.03 \\
94.1 \pm 0.03\end{array}$ & $\begin{array}{l}94.9 \pm 0.03 \\
89.6 \pm 0.05\end{array}$ & $\begin{array}{l}0.69 \mathrm{NS} \\
0.42 \mathrm{NS}\end{array}$ & $\begin{array}{l}-0.18 \\
-0.08\end{array}$ \\
\hline \multicolumn{6}{|l|}{ IV. Growth and reproduction } \\
\hline Biomass index (no. leaf pairs $\times$ largest leaf area) & 9 & $9.5 \pm 4.0$ & $14.5 \pm 3.0$ & $3.2^{*}$ & 0.34 \\
\hline Flowering index (at 170 days) & 8 & $1.35 \pm 0.2$ & $2.56 \pm 0.4$ & $2.8^{*}$ & 0.33 \\
\hline
\end{tabular}

$* P<0.05,{ }^{* * *} P<0.001$.

other parameters (Table 2); we omitted the latter in cumulative estimates to avoid bias arising from a lack of independence among related measures. We used repeated measure ANOvAs for variables measured multiple times (e.g. percentage germination).

\section{Results}

\section{Breeding system and pollination experiments}

The probability of fruit production varied with pollination treatment. Anther removal and the exclusion of pollinators generally resulted in the complete absence of fruit-set $(N=62)$. Only six flowers receiving such treatment during three years formed capsules; they averaged 1.17 seeds/capsule and all but one matured in our first study season when pollen contamination from anther excision was likely. In contrast, flowers bagged with intact anthers consistently produced autogamous fruit- and seeds (Figs 1 and 2). However, autogamous fruit set $(25-36 \%)$ was always lower than that of open$(54-86 \%)$ or hand-pollinated flowers $(52-77 \%$; Fig. 1). The fruit production of autogamous vs. open-pollinated flowers was statistically different in all years $(t=1.66$, $3.67,2.28 ; P=0.048,0.002,0.001)$ for arcsin-transformed data in 1982, 1986, 1996, respectively; one-tailed $t$-test for percentage data). Fruit-set also varied significantly among the four pollination groups in 1986 $\left(\chi_{3}^{2}=14.4, P<0.01\right)$ and $1996\left(\chi_{3}^{2}=8.5, P<0.05\right)$. Among-year differences in fruit-set for open-pollinated flowers were not significant $\left(\chi_{2}^{2}=2.8, P>0.05\right)$.
Seed production also varied with pollination mode during the two years that we gathered data on the number of filled seeds per capsule. In 1982, seed production in open-pollinated capsules was double that in bagged, autogamously selfed flowers that bore seed $\left(t_{37}=3.8, P<0.001\right.$; Fig. 2$)$. In contrast, in 1996, differences in seed number in open-pollinated vs. autogamously pollinated flowers were not significant $(P>0.05$, Tukey's HSD). Open-, self- and crosspollination treatments differed in seed production that year (ANOvA, $F_{2,34}=5.1, P=0.01$, Fig. 2 ), with significantly higher values for outcrossed than openpollinated flowers (Tukey's HSD). Open-pollinated capsules also set fewer seeds with a lower proportion of viable seeds than hand-pollinated selfs (Fig. 2). Although this difference was not significant $(P>0.05$, Tukey's HSD), the probability of Type II error is high given the losses of open-pollinated flowers to floral herbivory. Selfs and outcrosses provided pollen levels greater than those on open-pollinated stigmas, which had 17-86\% heterospecific pollen (Kephart et al. unpubl. data). Seed number did not differ for openpollinated flowers with or without anthers $\left(t_{35}\right.$, $P=0.59$ ), but was higher for flowers with intact anthers in pollinations matched by maternal parent with capsules of $>3$ seeds.

\section{Selfing rates}

In comparisons matched by maternal parent, we estimated a selfing rate of $0.38 \pm 0.08$ from seed viability 


\section{$\%$ Fruit production}

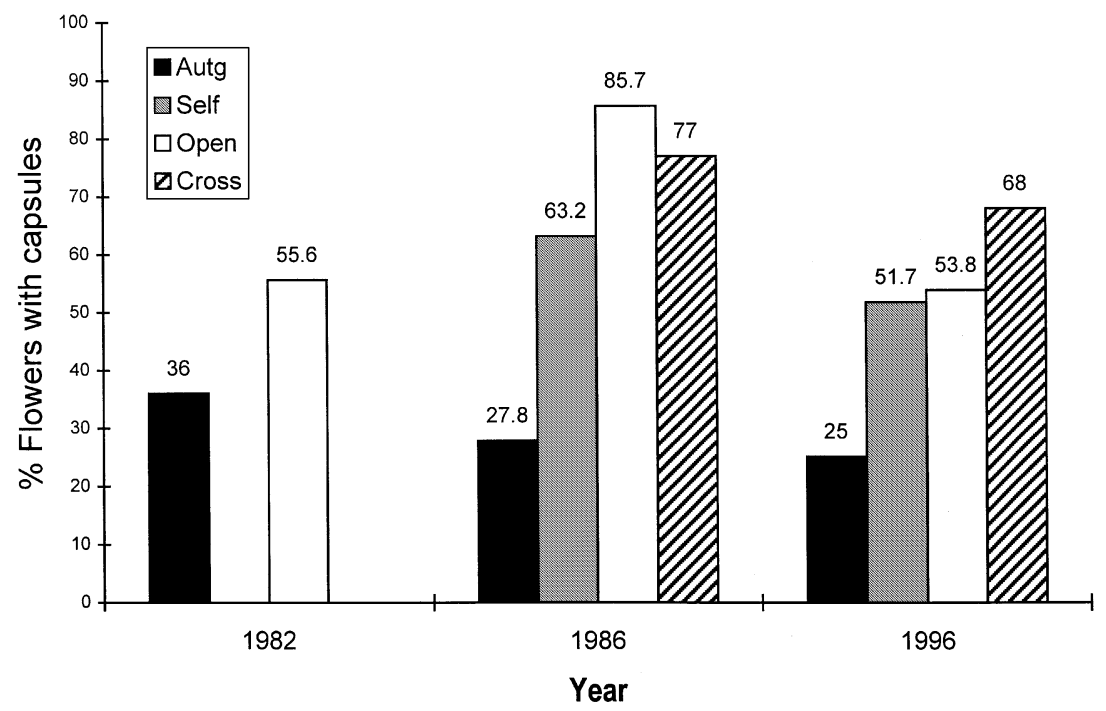

Fig. 1 The percentage of marked flowers of Silene douglasii var. oraria producing mature capsules after autogamy (netted), open-pollination, and hand self- and cross-pollination (netted). Pollen loads were standardized across hand-pollination treatments (see Materials and methods). and $0.26 \pm 0.11$ from germination. [If the latter is corrected for the loss of products of selfing during seed production (e.g. Mayer et al., 1996), the adjusted rate, $S_{0}$, for seed germination is 0.34 .] The selfing rate based on seed number was somewhat higher $(0.55 \pm 0.03)$, probably because the equations may overestimate $S$ if open-pollinated capsules fail to set seed or receive less pollen than selfs (Lande et al., 1994). Population means based on all progeny (vs. those matched by maternal parents) gave extremely high selfing rates $(S)$ : 1.55 (viable seed no. per capsule), 1.26 (percentage viable seed) and 1.14 (percentage germination). In Amsinckia, population estimates of selfing (e.g. $160 \%$ ) were also extreme, but only when the mean fitness for selfs and natural pollinations exceeded outcrosses (Johnston \& Schoen, 1996).

\section{Relative fitness and inbreeding depression}

Population means In trial 1, the capsules resulting from self-, open- and cross-pollinations differed significantly in fitness measures including the probability of fruit production, number of progeny (seeds matured per capsule), and percentage viable seeds (Fig. 3a). Crosspollinated flowers had a greater likelihood of fruit-set $(70 \%)$ than selfed $(46 \%)$ or open-pollinated $(53 \%)$ flowers $\left(\chi_{2}^{2}=8.6, \quad P<0.05\right)$. Similarly, crosspollinations yielded capsules with the highest filled seed

\section{Seed production}

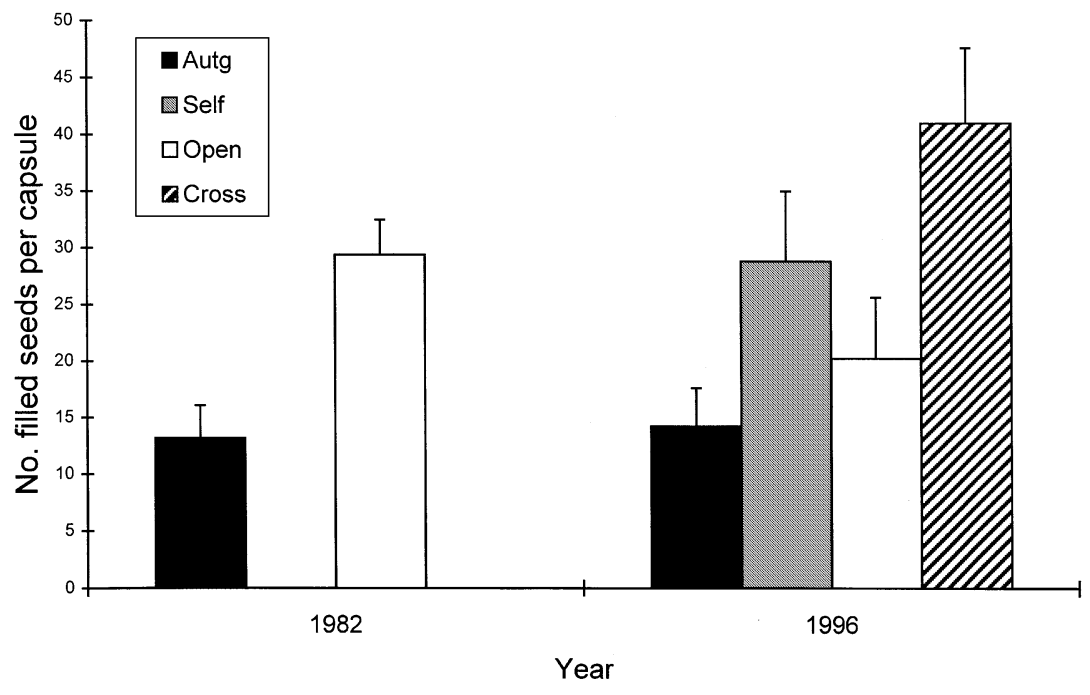

Fig. 2 The number of filled seeds produced per capsule $( \pm 1 \mathrm{SE})$ after autogamy, open-pollination, and hand selfand cross-pollination in Silene douglasii var. oraria.

(C) The Genetical Society of Great Britain, Heredity, 82, 543-554. 
Fig. 3 Comparison of character values at various life stages for trial 1 progeny of open-pollinated, and hand self- and cross-pollinated flowers of Silene douglasii var. oraria. (Asterisks denote characters exhibiting significant differences among treatments after one-way ANOvAs, $P<0.05$ ). (a) Characters include the probability of fruit production (Fprod), filled seed number/capsule for fruits with filled seeds only (Nseed) or also including capsules with only abortive seeds (NseedA), percentage viable seeds per capsule (Vseed), and mean seed weight (WSeed; $m g \times 10$ ). (b) Traits are 15- and 40-day germination (15dGer, 40dGer; percentage), 60-day survival (Surv; percentage), the inverse of number of days to first flowering $(\mathrm{NdyF} \times 1000)$, mean height $($ HtInfl; $\mathrm{cm}$ ) and number of flowers (Nflwr) of the first inflorescence, and the proportion of flowers that produced seed autonomously (AutSd) for glasshousegrown progeny.
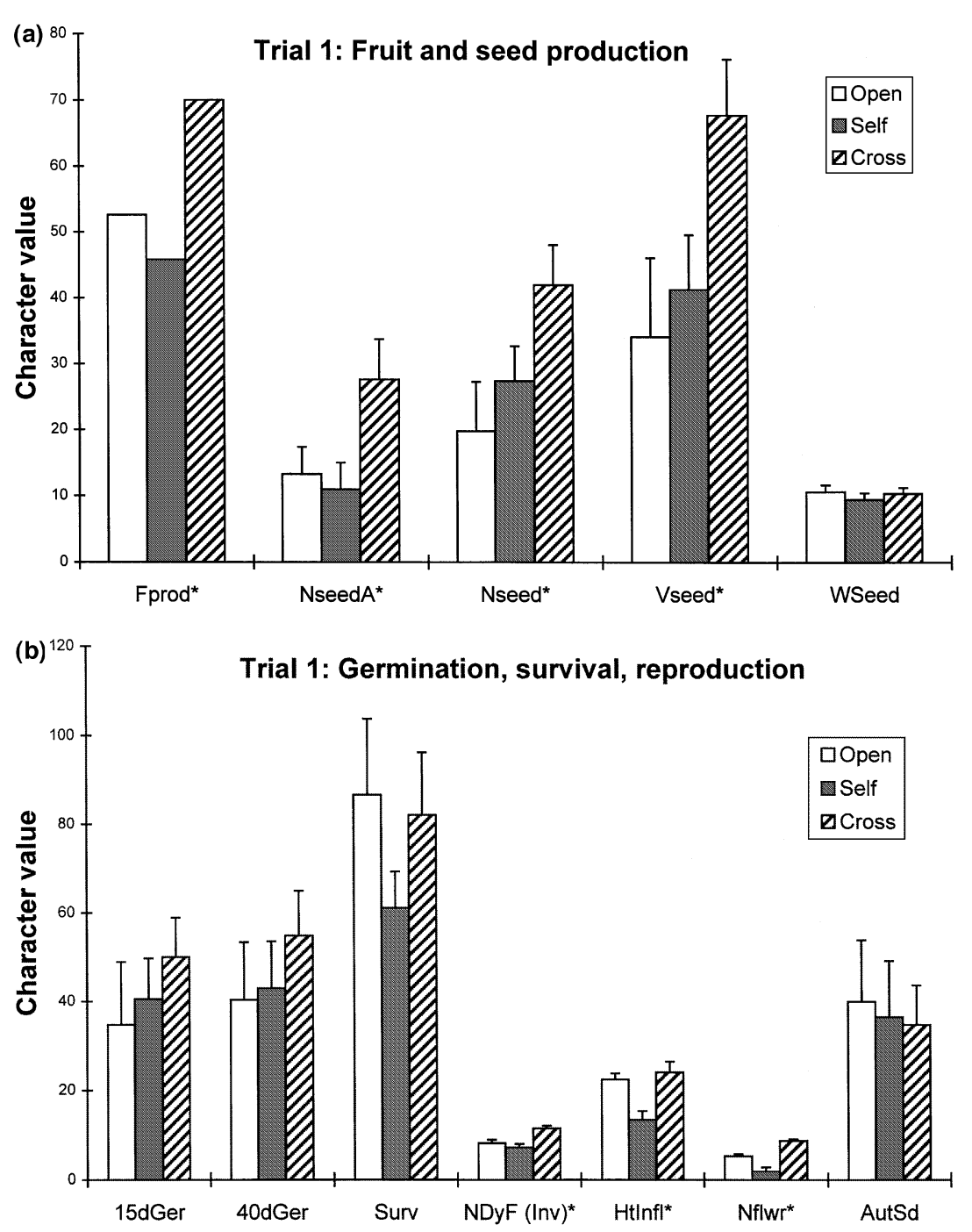

numbers (ANOVA, $F_{2,36}=3.75, P<0.05$ ), and with percentages of filled seeds relative to those aborted that were 1.6-2.0 times greater than for open- and selfpollinated flowers $\left(F_{2,30}=3.84, P<0.05\right)$, respectively. Mean seed weights $(0.94-1.06 \mathrm{mg})$ were not significantly different among treatments (ANOVA, $F_{2,40}=$ $0.37, P>0.05$; Fig. 3a), but capsules with few seeds $(<5)$ often had larger than average seed weights.

Random-selected progeny from capsules harvested in each pollination category (trial 1) but not paired by maternal family, also had higher 15- and 40-day percentage germination, a greater probability of survival to reproduction, and higher fecundity after outcrossing relative to selfing (Fig. 3b). However, sample sizes for germinable and surviving progeny were relatively low in this initial trial and differences among treatments were not significant $\left(F_{2,17}=0.46-0.62, P>0.05\right)$. In contrast, differences in fecundity among the 28 surviving plants were marked, with outbred progeny averaging fewer days to first flowering $\left(\chi_{2}^{2}=6.2, P=0.04\right.$, Kruskall-Wallis), greater inflorescence height (ANOvA, $\left.F_{2,20}=5.0, P=0.02\right)$, and more flowers $\left(\chi_{2}^{2}=17.1\right.$, $P<0.001$, Kruskal-Wallis) than inbred progeny (Fig. 3b). In fact, three of the inbred progeny produced no flowers in the first six months of growth. Levels of autonomous production of viable seeds by glasshouse progeny did not differ among treatments $\left(F_{2,20}=0.05\right.$, $P>0.05)$. The values of $35-40 \%$ exceeded those obtained in the field.

Trial 1 parameters measured throughout the life cycle provided the basis for population-wide estimates of relative fitness. Outcrossed progeny exceeded inbred progeny for all parameters, except autonomous production of seeds in the greenhouse (Fig. 3). The three-stage value for cumulative inbreeding depression (from seed number, 15-day germination and mean fecundity score $)$ was $0.85[1-(0.40 \times 0.81 \times 0.47)]$, well exceeding the 0.5 threshold favouring outbreeding. 


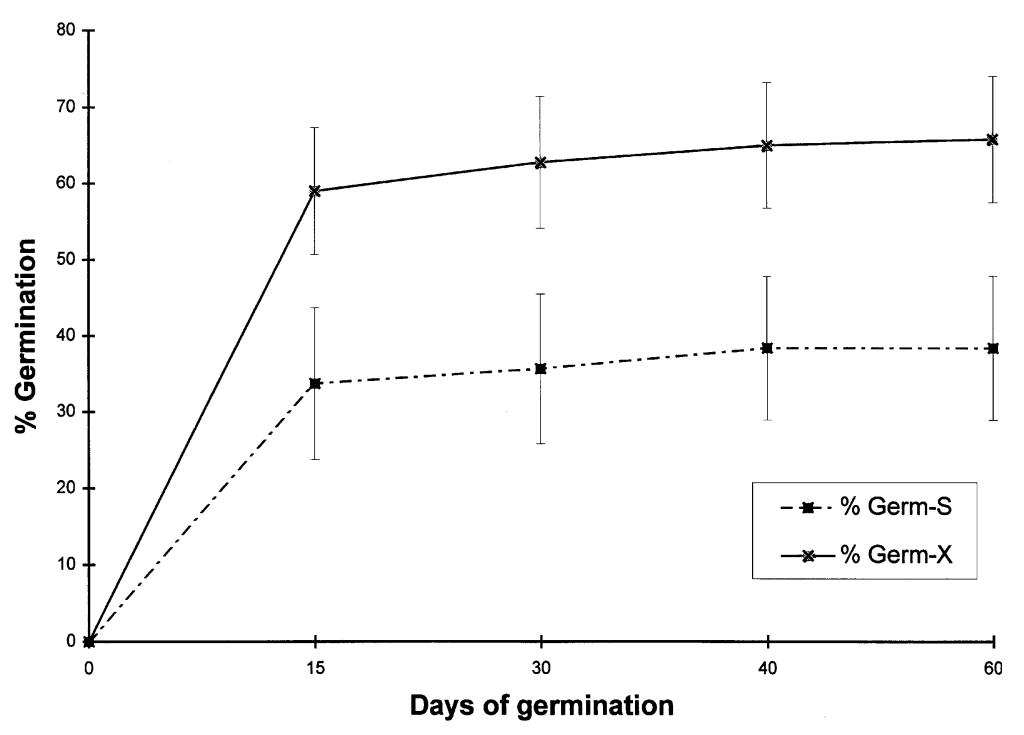

Fig. 4 Glasshouse germination rates for inbred and outbred progeny resulting from hand self- (S) and cross-pollinations $(\mathrm{X})$ performed in natural populations of Silene douglasii var. oraria. Differences among progeny types were significant for all measurement intervals (repeated measures ANOva, $P<0.05$ ).
Single-stage $\delta$-values based on inflorescence height (0.44) and days to flowering (0.38) were similar, but considerably lower than for flower number/inflorescence (0.78).

Estimates based on individual maternal plants: trial 2 Levels of inbreeding depression and relative fitness varied with life stage; except for survival, inbred progeny showed reduced fitness (Table 2). Measures of the effect of both early and late phases of seed production (i.e. early abortion of postfertilization embryos or endosperm failure in capsules with only aborted seeds) gave significant differences: seeds arising from outcrosses averaged twice the number produced after self-pollination (e.g. $31.4 \pm 6.7$ and $12.8 \pm 4.6$ seeds, respectively; paired $t_{17}=2.7, P<0.05$ ). The mean percentage viable seeds for outcrosses $(68.7 \pm 9.3)$ also significantly exceeded that of selfs (38.2 \pm 10.3 ; paired $t_{10}=2.4 ; \quad P<0.05$ ), but we detected no difference in seed weight, or seedling survival (Table 2).

Among other life stages, seed germination was highest and most rapid for outbred offspring (Fig. 4), and the fitness reductions for inbred progeny were similar for above-ground biomass (34\%) and flowering (33\%; Table 2). However, in all parameters except survival, maternal families showed considerable variability in fitness (Table 3). Moreover, families with high germination among outbred progeny also exhibited high germination for selfed progeny (Spearman rank correlation $=0.76, P<0.01)$. Rank correlations were not significantly different $(P<0.05)$ for seed production, survival, or biomass measures.

Cumulative inbreeding depression averaged $76 \%$ in trial 2 families, and $70 \%$ in calculations based on population means; it includes both early- (germination) and late-acting (biomass) components (Table 3). Cumulative inbreeding depression was slightly higher $(85 \%)$ for trial $1 ; \delta$ s for seed production $(0.35-0.60)$ and progeny fecundity (mean $=0.53$ ) exceeded both germination (0.22) and survival (0.26). The $10 \%$ lower cumulative inbreeding depression for trial 2 may reflect an underestimate of $\delta$ at seed production because we could follow only families with progeny surviving the entire life cycle (i.e. excluding those yielding only capsules with aborted seed, or for which only outbred progeny germinated successfully). If $\delta$ s for seed production are computed instead from the maternal families initially producing both inbred and outbred progeny (Table 2), values of $29-59 \%$ replace the $19 \%$ figure for surviving families (Table 3). Only in these latter families were we unable to detect significant differences in seedset for inbred and outbred progeny $\left(t_{7}=1.8\right.$, $P=0.12)$.

\section{Discussion}

\section{Silene as a mixed-mating system with partial selfing}

Silene douglasii clearly exhibits a mixed-mating system. Despite strong protandry and evident nectar and pollen production, up to $36 \%$ of bagged flowers produced capsules autogamously. We also observed high amongyear variability in fruit-set for open-pollinated flowers, with values equivalent to either selfing or outcrossing. Moreover, our best estimates of selfing $(S)$ in $S$. douglasii imply outcrossing rates $(45-66 \% ; t=1-S)$ in the range between obligate outcrossers and predominant selfers. To our knowledge, this represents the first examination of mating systems and inbreeding in a rare, 
Table 3 Cumulative multiplicative fitness and inbreeding depression $(\delta)$ in Silene douglasii var. oraria based on the product of relative fitnesses for selfed and outcross progeny at four stages: number of seeds per capsule, percentage seed germination (60 days), percentage seedling survival (germination to transplant at 2 months), and above-ground biomass index. Includes subset of maternal plants for which both the self and outcross progeny of in situ field-based crosses survived throughout the study

\begin{tabular}{|c|c|c|c|c|c|c|c|c|c|c|}
\hline Mat + & NSeed & $x$ & Germn & $x$ & Survl & $x$ & BiomI & $=$ & Cum fitness & $\begin{array}{c}\delta \\
(1-\text { CumFit })\end{array}$ \\
\hline 1 & 0.96 & & 0.54 & & 1.22 & & 0.47 & & 0.29 & 0.70 \\
\hline 2 & 1.54 & & 0.73 & & 0.93 & & 0.50 & & 0.52 & 0.48 \\
\hline 3 & 0.05 & & 1.00 & & 1.12 & & 1.46 & & 0.08 & 0.92 \\
\hline 4 & 1.10 & & 0.44 & & 1.00 & & 0.61 & & 0.30 & 0.70 \\
\hline 5 & 1.11 & & 0.41 & & 1.00 & & 0.45 & & 0.20 & 0.80 \\
\hline 6 & 0.78 & & 0.20 & & 1.00 & & 0.78 & & 0.12 & 0.88 \\
\hline 7 & 0.38 & & 0.92 & & 1.00 & & 0.46 & & 0.16 & 0.84 \\
\hline 8 & 0.55 & & 0.83 & & 0.88 & & 0.70 & & 0.28 & 0.72 \\
\hline Mean & 0.81 & & 0.63 & & 1.02 & & 0.68 & & 0.245 & 0.755 \\
\hline $\begin{array}{l}\text { Paired } t \\
(\text { d.f. }=7)\end{array}$ & 1.8 & & $3.9 * *$ & & 0.4 & & $3.2 * *$ & & & \\
\hline
\end{tabular}

$* * P<0.01$

strictly hermaphroditic Silene, despite the numerous rare taxa among North American silenes (Kephart \& Paladino, 1997), and abundant data on the evolution of dioecious and gynodioecious Silene and Caryophyllaceae (e.g. Jolls \& Chenier, 1989; Shykoff, 1992; Carroll \& Mulcahy, 1993; Sakai et al., 1997). The inbreeding depression we detected in var. oraria suggests several possibilities for studies of mating system evolution in rare or common perennials including Silene.

\section{Magnitude and timing of inbreeding depression}

Inbreeding depression was high in $S$. douglasii $(\delta=0.76)$, far surpassing the mean in outcrossing angiosperms ( $\delta=0.49$ ), but comparable to a subset of outcrossing perennials with cumulative four-stage values of 0.61-0.93 (e.g. Silene vulgaris, Schiedea, Decodon, Lupinus; Husband \& Schemske, 1996). Inbred progeny had a $48-92 \%$ reduction in cumulative fitness across maternal lines, and all stage-specific means except seedling survival exceeded reports for self-pollinating angiosperms (0.03-0.22; Husband \& Schemske, 1996). Small differences in survival are common, and may reflect the high quality and absence of competition in glasshouses, the equivalent scoring of robust and weak plants as survivors, or the absence of real differences in progeny survival (Dudash, 1990; Johnston \& Schoen, 1996).

The magnitude of inbreeding depression, when evident, varied with life-history stage. In $S$. douglasii, as in both selfing and outcrossing angiosperms, $\delta$ s (trial 2) were high for seed production (29-59\%), germination $(41 \%)$, and growth and reproduction (33-34\%). The overall distribution of early- and late-acting inbreeding depression is consistent with that of most outcrossers (Husband \& Schemske, 1996), except that, as in S. vulgaris, germination differences are of greater importance than in most plants (Jolls \& Chenier, 1989). Although families varied in the expression of stage-specific inbreeding depression, only germination performance was correlated between selfed and outcrossed progeny. Reciprocal crosses could distinguish whether this reflects differential provisioning of seeds among maternal parents, or similar zygotic expression of genes in inbred and outbred progeny (Lynch, 1988).

Variable measures of $\delta$ for seed production (Table 2) suggest that early acting inbreeding depression may be underestimated in self-compatible plants. The oftenused characters, percentage viable seeds and seed number/fruit, may not detect early, postfertilization effects if calculations exclude fruits with only aborted ovules. Seeds may abort because of late-acting, cryptic self-incompatibility unrelated to inbreeding (Seavey \& Bawa, 1986), but in Silene, the variable sizes of aborted ovules imply such maternal 'decisions' are less likely (i.e. failure probably occurs at different stages of embryo formation).

\section{Evolutionary implications of partial selfing, and high inbreeding depression}

An historically outcrossing mode of pollination is implied for $S$. douglasii var. oraria given strong dichogamy, 
intermediate selfing rates, the reproductive gains observed for outcrossed flowers, and the distribution of inbreeding depression across life-history stages. However, the outcomes of self- and open-pollination were often statistically similar for a range of fitness parameters (e.g. fruit and seed production, germination and days to first flowering), implying that considerable autogamy or facilitated selfing occurs in some years. So, what maintains selfing and high inbreeding depression in Silene and other cosexual plants with similar life histories?

Role of genecological factors and reproductive assurance In theory, a cumulative inbreeding depression of $76 \%$ will allow selfing to evolve in an initially panmictic population (Holsinger, 1988), but populations with $\delta$-values well exceeding 0.5 are expected to exhibit strong selection against it (Lande \& Schemske, 1985; Willis, 1993). Also, populations with a history of selfing or range restriction often lose early acting lethal recessives, thus lowering inbreeding depression (e.g. Latta \& Ritland, 1994; Runyeon \& Prentice, 1996). This has not occurred in Silene, but tetraploidy and/or temporal variation in insect-mediated outcrossing may increase the time required to purge lethal alleles (Lande \& Schemske, 1985; Holsinger, 1996).

Ecological factors may be important determinants of inbreeding depression, selfing rates, and mating system evolution (Lloyd, 1992; Uyenoyama et al., 1993; Johnston \& Schoen, 1996). Yet the degree to which selfing is maintained or selected for in outbred populations depends on how selfing occurs, the extent of pollen limitation of seed production, and any losses in outcross fitness by displacement during pollen and seed discounting (Lloyd, 1992; Uyenoyama et al., 1993). So when is selfing advantageous in an outcrossing perennial with high inbreeding depression?

In Silene, selfing occurs either in single flowers (via spontaneous or insect-facilitated selfing) or through geitonogamy, but geitonogamy and facilitated selfing are rarely advantageous and neither assures reproduction during pollinator scarcity (Lloyd, 1992; Holsinger, 1996). Strong protandry largely precludes delayed selfing, and reproductive efficiency is also an unlikely argument for selfing given the spatial separation of anthers and stigmas, temporal differences in their maturation, and low autogamous seed-set. In contrast, because anthers dehisce above the later developing stigmas, prior selfing is mechanically feasible and can be selected for if pollinator scarcity prevents crosspollination (hence losses to seed and pollen discounting are small), or if some self-pollen with low viability or competitive success is deposited before external pollen (Lloyd, 1992). In these scenarios, selfing could assure reproduction, thereby raising the threshold level of inbreeding depression below which selfing occurs (Lloyd, 1992; Holsinger, 1996; Ramsey \& Vaughton, 1996).

Although separating ongoing selective regimes from historical factors is difficult, the empirical evidence best supports a key role for reproductive assurance in the coexistence of partial selfing and high inbreeding depression in Silene. Small amounts of Silene pollen occur on stigmas (0-56 grains in 1996 vs. mean ovule number $=65$; unpubl. data), and seed production is low after strictly autonomous selfing, thus minimizing seed discounting that could otherwise offset fitness gains for selfing. Moreover, insects visit mostly male-phase flowers, and also deposit foreign pollen. Such ineffective, heterospecific pollen might influence selection for prior selfing, and deserves more empirical study in plants with high inbreeding depression.

Other arguments and evidence also imply that reproductive assurance merits further study in present-day $S$. douglasii and in other plants. First, although fruit production in open-pollinated flowers of Silene varies temporally, these flowers set equivalent or fewer seeds than selfed flowers with assured pollen loads, provide more fruit but only $6-16 \%$ more seed than spontaneous selfing, and yield about half the number of seeds of hand-outcrossed flowers $(P<0.05)$. These data and the relatively low seed-set in naturally pollinated plants imply that insufficient pollen often limits plant reproduction. This hypothesis is further supported by related studies of pollen addition, in which fruit and seed production were significantly greater for stigmas with larger pollen loads (Brown \& Kephart, unpubl. data).

Evolutionary patterns in breeding systems Although more empirical data are needed, the high inbreeding depression and selfing detected in $S$. douglasii suggest a possible avenue for the evolution of gynodioecy. Inbreeding depression is related to high selfing rates and the maintenance of females in gynodioecious Caryophyllaceae (e.g. Silene vulgaris, Jolls \& Chenier, 1989; Schiedea, Sakai et al., 1997). In var. oraria, genetic drift and the small number of extant populations might exacerbate any loss in variability associated with selfing, and potentially favour gynodioecy, which enforces partial outcrossing. Some flowers also possess abortive anthers (potentially sterile), and nearly simultaneous pollen and stigma presentation; thus, if heritable, the potential for shifts to either predominant selfing or gynodioecy exist from genetic and morphological standpoints. Both mating systems avoid a disadvantage of protandry in hermaphrodites - that effective pollination requires two visits - at anther shedding and stigma exsertion (Sun \& Ganders, 1986). In var. oraria the most 
common visitor rarely lands on female-phase flowers, despite high nectar levels relative to flowers with pollen (Kephart et al., unpubl. data). Under dichogamy, any selective advantage of outcrossing is lost if these single visits result merely in pollen theft, selfing, or heterospecific pollination.

\section{Conclusions and conservation implications}

Pollinators can be opportunistic visitors, and the mixed-mating system of var. oraria illustrates well the uncertainty of assuming an outcrossing "pollination syndrome' based on floral characters (Waser et al., 1996). Outcrossing and inbreeding depression are clearly influenced by habitat-mediated shifts in pollinator availability (Delph, 1990; Holsinger, 1996); thus, a mixed-mating system might provide an ESS of bethedging under adverse conditions while achieving the fitness gains associated with cross-pollination when visitors are abundant. Most rare perennials like $S$. douglasii depend on seed production to offset losses of reproductive potential or population declines that can result from ageing, competition and herbivory (Kephart \& Paladino, 1997). Presently, var. oraria populations appear to be at risk from low realized seed-set, inbreeding depression, and limited opportunity for genetic rescue (i.e. the few, extant populations are mostly small). Discovering whether Silene and other perennials with mixed-mating systems and strong dichogamy can indeed achieve effective, evolutionarily stable strategies is an important challenge, one which will require broad sampling in diverse species.

\section{Acknowledgements}

We thank colleagues J. Brunet, M. Carlson, K. Holsinger, A. Sakai and anonymous reviewers for helpful comments on drafts of this manuscript. Teresa Culley and D. Schemske also shared their knowledge in discussions, and E. Joines provided technical assistance with glasshouse populations. Field and laboratory assistants for pollination studies included K. Bledsoe, J. Bartholet, G. Mulder and A. Walton. Financial and logistical support was provided by the Atkinson Fund of Willamette University, The Murdock Trust, and The Nature Conservancy.

\section{References}

CARroll, S. B. AND MUlCAHY, D. L. 1993. Progeny sex ratios in Silene latifolia (Caryophyllaceae). Am. J. Bot., 80, 551-556. CHARLESWORTH, D. 1988. A method for estimating outcrossing rates in natural populations of plants. Heredity, 61, 469-471.
DELPH, L.F. 1990. The evolution of gender dimorphisms in New Zealand Hebe (Scrophulariaceae) species. Evol. Trends Plants, 4, 85-97.

DUDASH, M. R. 1990. Relative fitness of selfed and outcrossed progeny in a self-compatible, protandrous species, Sabatia angularis L. (Gentianaceae): a comparison in three environments. Evolution, 44, 1129-1139.

ECKERT, C. G. AND BARRETT, S. C. H. 1994. Inbreeding depression in partially self-fertilizing Decodon verticillatus (Lythraceae): population-genetic and experimental analyses. Evolution, 48, 952-964.

ECKERT, C. G. AND SCHAEFFER, A. 1998. Does self-pollination provide reproductive assurance in Aquilegia canadensis (Ranunculaceae). Am. J. Bot., 85, 919-924.

HOLSINGER, K. E. 1988. Inbreeding depression doesn't matter: the genetic basis of mating system evolution. Evolution, 42, 1235-1244.

HOLSINGER, K. E. 1996. Pollination biology and the evolution of mating systems in flowering plants. Evol. Biol., 29, 107-149.

HUSBAND, B. C. AND SCHEMSKE, D. W. 1996. Evolution of the magnitude and timing of inbreeding depression in plants. Evolution, 50, 54-70.

JARNE, P. AND CHARLESWORTH, D. 1993. The evolution of the selfing rate in functionally hermaphrodite plants and animals. Ann. Rev. Ecol. Syst., 24, 441-466.

JENNERsten, O. 1988. Pollination of Viscaria vulgaris (Caryophyllaceae): the contributions of diurnal and nocturnal insects to seed set and seed predation. Oikos, 52, 319-327.

JOHNSTON, M. O. AND SCHOEN, D. J. 1994. On the measurement of inbreeding depression. Evolution, 48, 1735-1741.

JOHNSTON, M. O. AND SCHOEN, D. J. 1996. Correlated evolution of self-fertilization and inbreeding depression: an experimental study of nine populations of Amsinckia (Boraginaceae). Evolution, 50, 1478-1491.

JOLLS, C. L. AND CHENIER, T. C. 1989. Gynodioecy in Silene vulgaris (Caryophyllaceae): progeny success, experimental design, and maternal effects. Am. J. Bot., 76, 1360-1367.

KEPHART, S. R. AND PALADINO, C. 1997. Demographic change and microhabitat variability in a grassland endemic, Silene douglasii var. oraria (Caryophyllaceae). Am. J. Bot., 84, 179-189.

LANDE, R. AND SCHEMSKE, D. W. 1985. The evolution of selffertilization and inbreeding depression in plants. I. Genetic models. Evolution, 39, 24-40.

LANDE, R., SCHEMSKe, D. W. AND SCHUltz, S. T. 1994. High inbreeding depression, selective interference among loci, and the threshold selfing rate for purging recessive lethal mutations. Evolution, 48, 965-978.

LATTA, R. AND RITLAND, K. 1994. The relationship between inbreeding depression and prior inbreeding among populations of four Mimulus taxa. Evolution, 48, 806-817.

LEsICA, P. 1993. Loss of fitness resulting from pollinator exclusion in Silene spaldingii (Caryophyllaceae). Madroño, 40, 193-201.

LLOYD, D. G. 1992. Self- and cross-fertilization in plants. II. The selection of self-fertilization. Int. J. Pl. Sci., 153, 370-380.

LYNCH, M. 1988. Design and analysis of experiments on random drift and inbreeding depression. Genetics, 120, 791-807. 
MAYER, S. S., CHARLESWORTH, D. AND MEYERS, B. 1996. Inbreeding depression in four populations of Collinsia heterophylla Nutt. (Scrophulariaceae). Evolution, 50, 879891.

NEWMAN, D. AND PILSON, D. 1997. Increased probability of extinction due to decreased genetic effective population size: experimental populations of Clarkia pulchella. Evolution, 51, 354-362.

NORMAN, J. K., SAKAI, A. K., WELLER, S. G. AND DAWSON, T. E. 1995. Inbreeding depression in morphological and physiological traits of Schiedea lydgatei (Caryophyllaceae) in two environments. Evolution, 49, 297-306.

NORMAN, J. K., WELlER, S. G. AND SAKAI, A. K. 1997. Pollination biology and outcrossing rates in hermaphroditic Schiedea lydgatei (Caryophyllaceae). Am. J. Bot., 84, 641-648.

PETTERSSON, M. w. 1991. Pollination by a guild of fluctuating moth populations: option for unspecialization in Silene vulgaris. J. Ecol., 79, 591-604.

PIPER, J. G., CHARLESWORTH, B. AND CHARLESWORTH, D. 1986. Breeding system evolution in Primula vulgaris and the role of reproductive assurance. Heredity, 56, 207-217.

RAMSEY, M. AND VAUGHTON, G. 1996. Inbreeding depression and pollinator availability in a partially self-fertile perennial herb Blandfordia grandiflora (Liliaceae). Oikos, 76, 465-474.

RUNYEON, H. AND PRENTICE, H. C. 1996. Genetic structure in the species-pair Silene vulgaris and S. uniflora (Caryophyllaceae) on the Baltic island of Oland. Ecogr., 19, 181-193.

SAKAI, A. K., WEller, S. G., CHEN, M.-L., CHOU, S.-Y. AND TASANONT, C. 1997. Evolution of gynodioecy and maintenance of females: the role of inbreeding depression, out- crossing rates, and resource allocation in Schiedea adamantis (Caryophyllaceae). Evolution, 51, 724-736.

SCHOEN, D. J., JOHNSTON, M. O., L'HEUREUX, A.-M. AND MARSOLAIS, J. V. 1997. Evolutionary history of the mating system in Amsinckia (Boraginaceae). Evolution, 51, 1090-1099.

SEAVEY, S. R. AND BAWA, K. S. 1986. Late-acting self-incompatibility in angiosperms. Bot. Rev., 52, 195-219.

SHykofF, J. A. 1992. Sex polymorphisms in Silene acaulis (Caryophyllaceae) and the possible role of sexual selection in maintaining females. Am. J. Bot., 79, 138-143.

SUN, M. AND GANDERS, F. R. 1986. Female frequencies in gynodioecious populations correlated with selfing rates in hermaphrodites. Am. J. Bot., 73, 1645-1648.

UYENOYAMA, M. K., HOLSINGER, K. E. AND WALLER, D. M. 1993. Ecological and genetic factors directing the evolution of selffertilization. Oxf. Surv. Evol. Biol., 9, 327-381.

WALLER, D. M. 1993. The statics and dynamics of mating system evolution. In: Thornhill, N. W. (ed.) The Natural History of Inbreeding and Outbreeding, Theoretical and Empirical Perspectives, pp. 97-117. University of Chicago Press, Chicago.

WASER, N. M., CHITTKA, L., PRICE, M. V., Williams, N. AND OLlerton, J. 1996. Generalization in pollination systems and why it matters. Ecol., 77, 1043-1060.

WILLIS, J. H. 1993. Effects of different levels of inbreeding on fitness components in Mimulus guttatus. Evolution, 47, 864876.

YOUNG, H. J. AND YOUNG, T. P. 1992. Alternative outcomes of natural and experimental high pollen loads. Ecology, 73, 639-637.

ZIMMERMAN, M. AND PYKE, G. H. 1988. Reproduction in Polemonium: assessing the factors limiting seed set. Am. Nat., 131, 723-738. 